\title{
Desenvolvimento de geleia de tamarillo contendo polpa integral
}

\author{
Development of tamarillo jam containing whole pulp
}

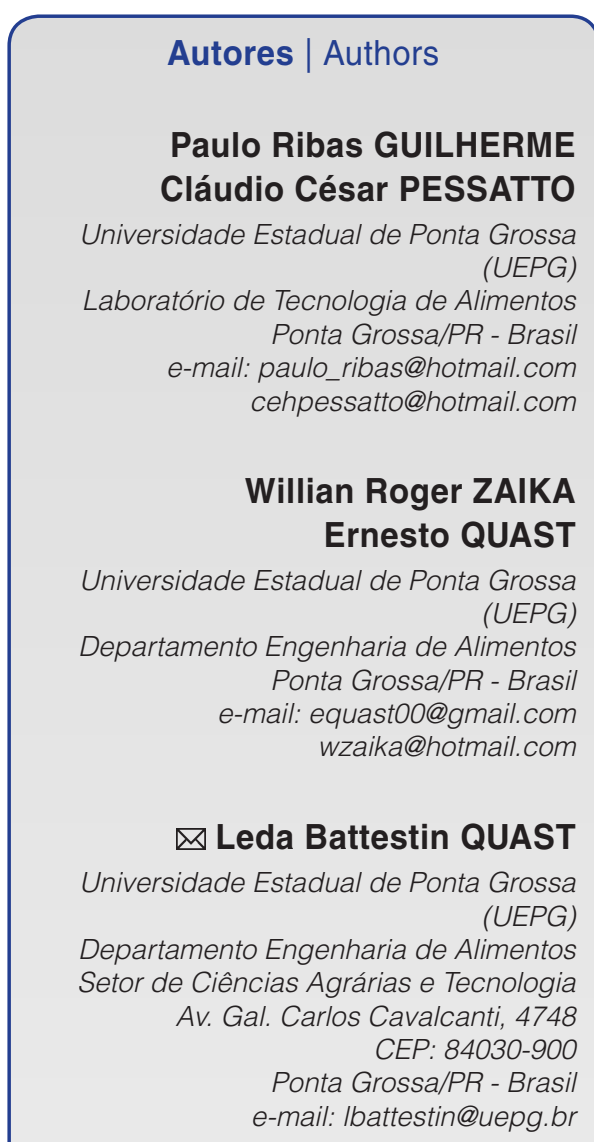

\section{Rita de Cássia Salvucci Celeste ORMENESE}

Instituto de Tecnologia de Alimentos (ITAL)

Unidade Laboratorial de Referência de

Análises Físicas, Sensoriais e Estatística Campinas/SP - Brasil e-mail: ritaorm@ital.sp.gov.br

\section{Dorivaldo da Silva RAUPP}

Universidade Estadual de Ponta Grossa (UEPG)

Departamento de Engenharia de Alimentos Ponta Grossa/PR - Brasil e-mail: raupp@uepg.br

Autor Correspondente / Corresponding Author

Recebido / Received: 09/05/2011 Aprovado / Approved: 28/02/2012

Publicado / Published: jun./2012

\section{Resumo}

O tamarillo (Cyphomandra betacea Sendt) é originário da Região Andina do Peru. O objetivo deste trabalho foi desenvolver o produto 'geleia de tamarillo' e consistiu em: caracterizar os frutos e o seu rendimento em polpa; apresentar um protocolo de processo, e avaliar sensorialmente os produtos obtidos a partir de três formulações, diferenciadas quanto ao grau ${ }^{\circ}$ Brix, ao tipo de açúcar e ao teor de pectina. Os frutos tamarillos apresentaram 54,8 $\pm 4,0 \mathrm{~mm}, 34,6 \pm 2,4 \mathrm{~mm}$ e 36,2 $\pm 6,5 \mathrm{~g}$ de comprimento, diâmetro e massa, respectivamente. A polpa integral, de sabor doce e levemente ácida, apresentou 13,30 $\pm 0,14{ }^{\circ} \mathrm{Brix}$ e $\mathrm{pH}$ $4,19 \pm 0,11$. Os frutos renderam $83,3 \%$ de polpa integral e $51,5 \%$ de locular mucilaginosa, contendo sementes. As geleias de $50^{\circ}$ Brix e contendo glicose ou sacarose foram as mais aceitas pelos provadores quando comparadas à geleia de $40{ }^{\circ}$ Brix, de menor concentração de sólidos solúveis. Um porcentual maior ou igual a $70 \%$ do total de provadores aprovou as geleias de $50^{\circ}$ Brix para todos os seus atributos sensoriais avaliados e um mínimo de $40 \%$ manifestou intenção de compra. Considerando-se que a sacarose possui custo menor que a glicose, o protocolo de fabricação da geleia de $50{ }^{\circ}$ Brix contendo a sacarose e $2 \%$ de pectina foi o recomendado, na pesquisa, para a produção de geleia de tamarillo.

Palavras-chave: Cyphomandra betacea Sendt; Tamarillo; Geleia.

\section{Summary}

The Tamarillo (Cyphomandra betacea Sendt) is a fruit native to the Peruvian Andean region. The objective of this study was to develop the product 'tamarillo jam'. The study consisted of characterizing the fruits and their yield in pulp; presenting a protocol for the process; and carrying out a sensory analysis of three different formulations which differed according to their degree of ${ }^{\circ}$ Brix, type of sugar and pectin content. The tamarillo fruits showed length (stem-apex), diameter and mass of $54.8 \pm 4.0 \mathrm{~mm}, 34.6 \pm 2.4 \mathrm{~mm}$ and $36.2 \pm 6.5 \mathrm{~g}$, respectively. The whole pulp had a sweet, slightly acid taste, with total soluble solids of $13.30^{\circ} \mathrm{Brix} \pm 0.14$ and $\mathrm{pH} 4.19 \pm 0.11$. The fruits yielded $83.3 \%$ in whole pulp and $51.5 \%$ in mucilaginous pulp containing the seeds. Jams with $50^{\circ}$ Brix containing glucose or sucrose showed greater acceptance as compared to jams with $40^{\circ} \mathrm{Brix}$, containing less soluble solids. Over $70 \%$ of the panellists approved the jams with $50^{\circ}$ Brix for all the sensory attributes evaluated, and at least $40 \%$ expressed their intention to purchase it. Thus, considering the lower cost of sucrose as compared to glucose, the protocol for the production of tamarillo jam at $50^{\circ}$ Brix using sucrose and $2 \%$ of pectin was recommended.

Key words: Cyphomandra betacea Sendt; Tamarillo; Jam. 


\section{Introdução}

O Brasil está entre os três maiores produtores mundiais de frutas, perdendo apenas para a China e a Índia, sendo que, no ano de 2007, exportou 920 mil toneladas (IBRAF, 2008). A fruticultura no Brasil possui um grande número de frutas nativas e exóticas, pouco exploradas economicamente (KISS, 2003).

Segundo Lourenzani et al. (2004), a agricultura familiar apresenta grande importância social e econômica, assim como fragilidades e potencialidades. É incontestável a sua capacidade de gerar renda e emprego, além da importante contribuição para a produção agropecuária. No entanto, é depositária de um grande contingente de pessoas vivendo em condições sociais e de produção extremamente heterogêneas, muitas vezes, formando bolsões de pobreza rural. Dentro desse contexto, em todo o mundo, nas regiões onde se cultivam frutas, principalmente para o consumo in natura, é onde ocorre a melhor distribuição de renda no meio rural e onde existe a melhor qualidade de vida. A fruticultura gera elevada renda por área e tem capacidade de absorver muita mão de obra quando comparada a outras atividades agrícolas.

O tamarillo (Cyphomandra betacea Sendt) é, segundo Morton (1982), originário da Região Andina da América do Sul. No Brasil, é conhecido por tomate-deárvore ou tomate francês. Em 1970, o nome "tamarillo" foi adotado na Nova Zelândia, onde era cultivado em pequena escala desde 1920, sendo que, em 1967, alcançou uma produção anual de duas toneladas. Em regiões como a Nova Zelândia e a Colômbia, é cultivado para comercialização como fruto in natura e matériaprima de processamento de doces, conservas e bebidas fermentadas (MANZANO, 2005; ROGER et al., 2007). No Brasil, o fruto continua pouco conhecido: na Bahia, recebe o nome de "tomatão"; em São Paulo, de "tomate francês", e na região sul de Minas Gerais é popularmente conhecido como "tomate-de-árvore". Com relação à sua comercialização, pode ser encontrado em alguns mercados das Regiões Sul e Sudeste, provenientes de importações.

A árvore do tamarillo, segundo Morton (1982), se desenvolve melhor em clima subtropical, em temperatura acima dos $10{ }^{\circ} \mathrm{C}$ e em clima mais frio em menores altitudes. A planta é pequena, semilenhosa, de crescimento rápido, raiz pouco profunda, podendo atingir 3-5,5 $\mathrm{m}$ de altura e, raramente, até $7,5 \mathrm{~m} \mathrm{~A}$ árvore começa a dar frutos normalmente com 1,5-2 anos e continua a ser produtiva durante 5 ou 6 anos; contudo, quando tratada adequadamente, pode manter a frutificação por 10-12 anos. No Brasil, cada árvore pode produzir de $20-30 \mathrm{~kg}$ de frutos por ano. O fruto, com tamanho de 5-10 cm de comprimento (pedúnculo-ápice) e 3,7-5 cm de diâmetro, é pendurado por um longo talo e se desenvolve unicamente ou em cachos de 3-12 frutos.
A coloração do fruto pode ser roxa, vermelha, alaranjada, amarela e vermelho amarelada, e pode apresentar listras longitudinais escuras e fracas. A polpa apresenta coloração que varia de laranja avermelhado ou laranja até amarelo-creme. O fruto apresenta pele resistente, uma camada de polpa mais externa compacta, firme e insossa, e uma polpa interna envolvendo as sementes, que é macia, suculenta, levemente ácida e adocicada. Frutos tamarillos produzidos no Equador, na Guatemala e na Índia apresentaram teores de umidade de 82,7$87,8 \mathrm{~g} .100 \mathrm{~g}^{-1}$ e as seguintes proporções de nutrientes, por $100 \mathrm{~g}^{-1}$ : proteínas $1,5 \mathrm{~g}$; carboidratos $10,3 \mathrm{~g}$; lipídios 0,08-1,28 g; fibra bruta 1,4-4,2 g; minerais totais 0,61-0,84 g; cálcio 3,9-11,3 mg; fósforo 13,1 mg; ferro 0,66-0,94 mg; caroteno 0,371-0,653 mg; tiamina 0,038$137 \mathrm{mg}$; riboflavina 0,035-0,048 mg; niacina 1,011 mg, e ácido ascórbico 23,3-33,9 mg.

O tamarillo também é fonte de substâncias antioxidantes, como antocianinas e flavonoides, de solasodina e tomatidenol, alternativas de esteroides de interesse farmacêutico, com propriedades medicinais para uso no combate a doenças respiratórias, anemia, afecções do fígado, diabetes e reumatismo (MANZANO, 2005; MORTON, 1982; ROGER et al., 2007).

O processamento de geleia exige poucos equipamentos e traz como vantagens para o setor produtivo, além de ser um produto de boa conservação, o aproveitamento de frutas impróprias para a comercialização in natura, em compota ou desidratada. Também permite o uso do excedente da produção (LOPES, 2007).

Segundo Jackix (1988), na geleia, a maior proporção de sólidos se deve ao açúcar solúvel, ingrediente e da fruta. Portanto, frutas contendo altos teores de sólidos solúveis implicam em menor adição de açúcar. Os ácidos orgânicos da fruta, representando pequenas proporções, conferem ao produto um gosto ácido.

Os Regulamentos Técnicos constantes da Resolução n 272 (BRASIL, 2005) estabelecem que geleia de fruta é o produto obtido pela cocção de frutas, inteiras ou em pedaços, polpa ou suco de fruta, com açúcar e água, e concentrado até a consistência gelatinosa. $\mathrm{Na}$ geleia, pode ser adicionado glicose ou açúcar invertido, acidulante e pectina. Quanto à consistência, ao ser extraída de seu recipiente, deve se manter no estado semissólido (gelatinoso). A cor e o aroma devem ser próprios da fruta e o sabor deve ser doce e levemente ácido.

A doçura de alguns carboidratos é uma das propriedades mais reconhecidas e mais agradáveis desses sólidos. Atribuindo à sacarose o valor padrão de doçura relativa de 100, a glicose recebe valores relativos de doçuras de 40 a 79 (RIBEIRO e SERAVALLI, 2007). 
O presente trabalho teve como objetivo desenvolver um produto à base de tamarillo, a 'geleia de tamarillo'. A proposta consistiu em caracterizar o fruto tamarillo e a sua polpa, bem como apresentar um protocolo de caracterização do processo de fabricação dessa geleia. Também avaliou sensorialmente os produtos obtidos a partir de três formulações de processo, diferenciadas quanto ao grau ${ }^{\circ}$ Brix, ao tipo de açúcar e ao teor do ingrediente pectina.

\section{Material e métodos}

Os frutos tamarillo, matéria-prima (Figura 1), foram coletados nos meses de março a junho de 2010 em árvores não cultivadas, na cidade de Ponta Grossa-PR, sendo arrancados com simples movimentos rotativos e mantendo-se os pedúnculos aderidos aos frutos.

Os experimentos de processamento para a obtenção do produto 'geleia de tamarillo' foram conduzidos em triplicata por tratamento, nas instalações do Departamento de Engenharia de Alimentos, da Universidade Estadual de Ponta Grossa. A matériaprima foi mantida sob refrigeração, em geladeira, em temperatura de $12 \pm 3{ }^{\circ} \mathrm{C}$, até atingir o ponto ideal de maturação, com coloração predominantemente laranja ou laranja avermelhada. Os frutos foram selecionados visualmente, tendo sido removido o pedúnculo e descartados aqueles com apodrecimento e danificados por insetos. Apenas os frutos maduros e em bom estado de conservação foram aproveitados.

Oitenta frutos de tamarillo foram utilizados para a avaliação do comprimento pedúnculo-ápice, diâmetro e massa. Para tanto, foram utilizados paquímetro com precisão de $0,05 \mathrm{~mm}$ e balança digital com precisão de $0,01 \mathrm{~g}$. A polpa integral (com as sementes) de 30 frutos foi

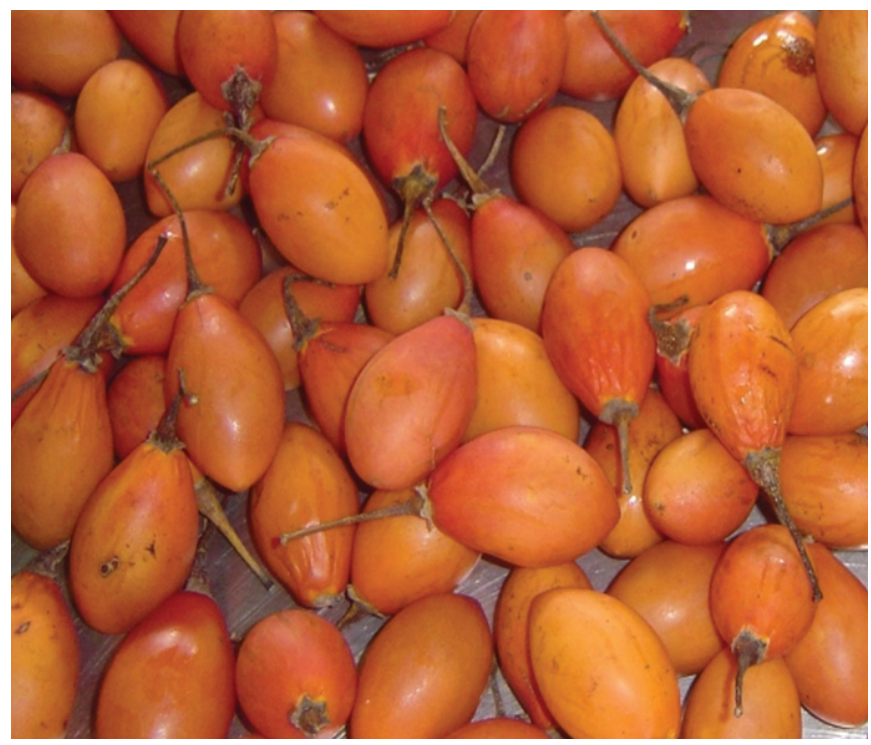

Figura 1. Frutos de tamarillo em mesa de processamento para seleção visual. caracterizada, em triplicata, quanto ao pH e aos sólidos solúveis totais (em ${ }^{\circ} \mathrm{Brix}$ ), utilizando-se medidor de $\mathrm{pH}$ marca PHTeC, modelo pHS-3B, e refratômetro manual com escala de 0-35 da marca ATAGO. Foi determinado o rendimento do fruto em polpa integral e locular, ambas contendo sementes.

Na lavagem dos frutos com água potável, foi usada uma esponja para remoção de sujidades e contaminantes aderidos à casca. Os frutos permaneceram imersos por 15 minutos em água clorada contendo $0,02 \mathrm{~g} \cdot \mathrm{L}^{-1}$ de cloro ativo e, a seguir, foram enxaguados em água potável. Os frutos foram agrupados em três lotes de 48 unidades e com massas muito próximas para o processamento das 'geleias de tamarillo', constituindo assim três tratamentos: tratamento 1, geleia de $40^{\circ}$ Brix contendo glicose; tratamento 2, geleia de $50{ }^{\circ}$ Brix contendo glicose, e tratamento 3 , geleia de $50^{\circ}$ Brix contendo sacarose.

Os ingredientes utilizados para o processamento das geleias de tamarillo foram: polpa integral do fruto tamarillo, sacarose ou glicose, pectina cítrica em pó da marca Vetec e água. Em cada processo, a polpa de tamarillo ( $40 \%$ da massa total da geleia) foi misturada com quantidades específicas, obtidas por cálculo, dos demais ingredientes. Uma quantidade de água excedente, potável e previamente fervida, foi usada para solubilizar os ingredientes e foi evaporada durante o tempo em que o produto permaneceu sob aquecimento. Durante a cocção, a massa da mistura foi homogeneizada continuamente com auxílio de uma espátula plástica e mantida em fervura por 40 minutos, sendo o seu ${ }^{\circ}$ Brix final 40 ou 50.

A massa do produto final foi monitorada usando-se balança de precisão e, para o envase a quente, foram usadas embalagens de vidro com capacidade, em massa de água, de $255 \mathrm{~g}$. As embalagens permaneceram, previamente, em água fervente por 30 minutos. O produto foi envasado ainda quente nos potes de vidro. As tampas metálicas foram apoiadas sobre o pote por 60 segundos, para permitir adequada exaustão do vapor de água. Após esse período, as tampas foram fechadas em definitivo e as embalagens invertidas por 5 minutos, para pasteurização da tampa metálica. Após esse procedimento, o produto final foi identificado como tratamento 1, 2 ou 3 e deixado esfriar em temperatura ambiente, mantendo-se uma distância entre os potes, para permitir o resfriamento com o ar ambiente (SOLER et al., 1995).

Para a avaliação sensorial dos produtos 'geleias de tamarillo', foram recrutados - dentre funcionários e estagiários do Instituto de Tecnologia de Alimentos (ITAL), situado na cidade de Campinas-SP - 50 consumidores de geleias de frutas, com idade entre 18 e 60 anos, das classes sociais $A, B$ e $C$, segundo o Critério Padrão de Classificação Econômica Brasil 2008 (ABEP, 2007). 
Os 50 consumidores recrutados para a avaliação sensorial do produto 'geleia de tamarillo', dividiram-se, segundo o gênero, em 39 mulheres e 11 homens. As características do grupo quanto à faixa etária e à classe social, estão apresentadas na Figura 2; a frequência de consumo de geleias e os sabores consumidos estão apresentados na Figura 3.

As amostras foram avaliadas quanto aos aspectos de aceitabilidade global, aparência, aroma, sabor, consistência na boca e espalhabilidade em torrada, por meio de escala hedônica de nove pontos $(9=$ gostei muitíssimo, 5 = não gostei nem desgostei e 1 = desgostei muitíssimo); o umedecimento em pão de forma foi avaliado por meio de escala do ideal de cinco pontos ( 5 = muito mais intenso do que eu gosto, 3 = do jeito que eu gosto, 1 = muito menos intenso do que eu gosto); a intenção de compra por meio de escala de cinco pontos $(5=$ certamente compraria, $3=$ talvez comprasse, talvez não comprasse, $1=$ certamente não compraria) (MEILGAARD et al., 2006). Foi solicitado aos consumidores que descrevessem o que mais gostaram e o que menos gostaram em cada uma das amostras avaliadas.

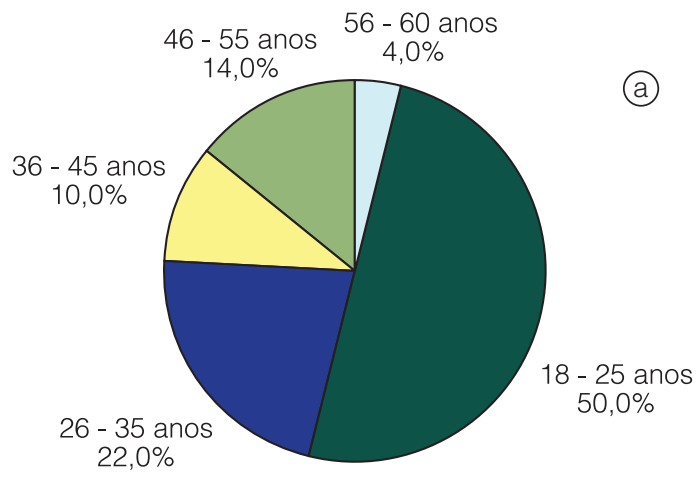

As amostras foram avaliadas de forma monádica sequencial, segundo delineamento de blocos completos balanceados. Visando limpar o palato, foi oferecida água mineral natural para uso antes e entre as amostras. Os testes foram conduzidos em cabines individuais com iluminação de lâmpadas fluorescentes e equipadas com o sistema computadorizado Compusense Five versão 4.8 para coleta e análise dos dados, os quais foram submetidos à análise de variância e ao teste de Tukey para comparação de médias.

Além das questões relacionadas à avaliação dos produtos, os consumidores responderam a questões sobre sua faixa etária e seus hábitos de consumo de geleia.

\section{Resultados e discussão}

Os frutos tamarillos apresentaram no estádio imaturo coloração verde ou verde arroxeada; durante a maturação, adquiriram coloração laranja ou laranja avermelhada, com predominância de frutos Iaranja avermelhados, os quais representaram $59,0 \%$ de um total de 144 frutos. Os frutos apresentaram $54,8 \pm 4,0 \mathrm{~mm}$, $34,6 \pm 2,4 \mathrm{~mm}$ e 36,2 \pm 6,5 g de comprimento (pedúnculo-

Figura 2. Faixa etária (a) e classe social (b) do grupo de consumidores que avaliou as amostras.
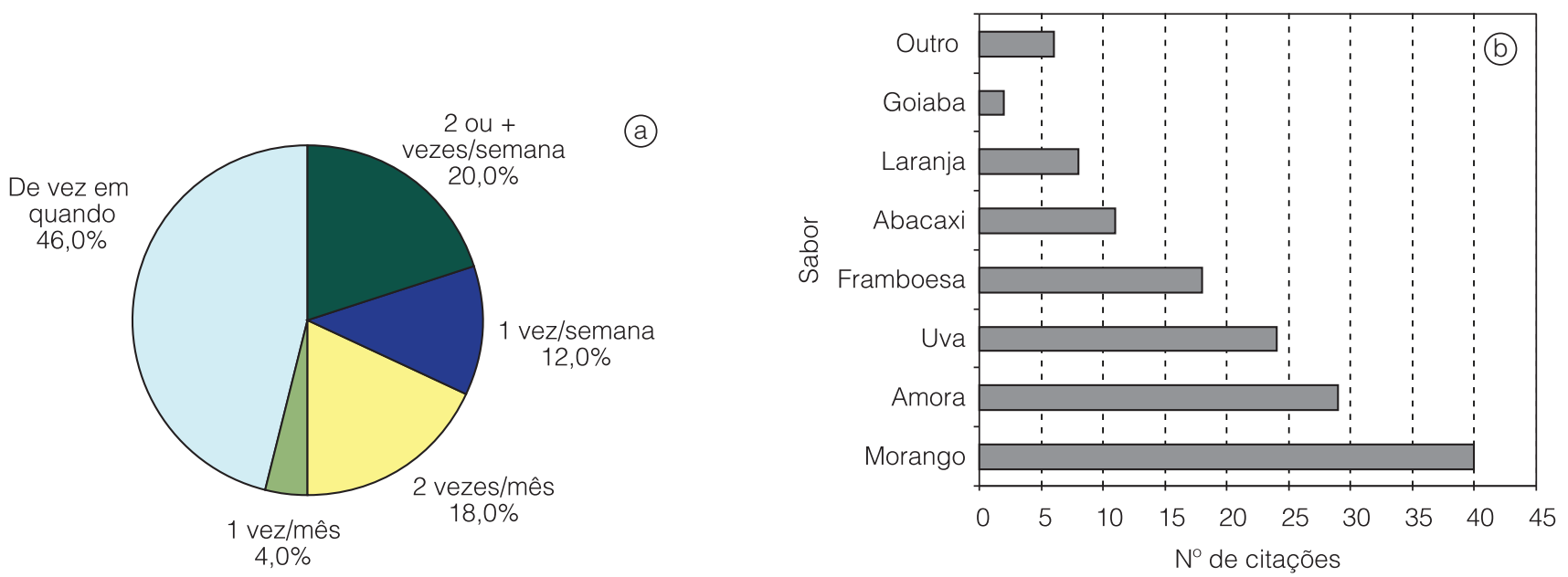

Figura 3. Frequência de consumo (a) e sabores de geleias consumidas (b) pelo grupo que avaliou as amostras. 
ápice), diâmetro e massa, respectivamente. Das três características avaliadas, a massa dos frutos foi a que teve a maior variação.

O teor de sólidos solúveis da polpa integral teve valor médio de 13,30 $\pm 0,14{ }^{\circ} \mathrm{Brix}$, indicando que os frutos quando maduros apresentaram uniformidade em relação aos solutos. A polpa apresentou um $\mathrm{pH}$ médio de $4,19 \pm 0,11$, sendo considerado como levemente ácido. Essas características de ${ }^{\circ}$ Brix e pH são responsáveis por conferir sabor doce e levemente ácido à polpa do fruto tamarillo.

Frutos tamarillos da Venezuela avaliados por Manzano (2005), quatro cultivados e um silvestre, mostraram-se maiores do que os desta pesquisa, apresentando, respectivamente: comprimento de 62,2$68,5 \mathrm{~mm}$ a 83,1 mm; diâmetro de 47,2-59,8 mm a $37,5 \mathrm{~mm}$; massa de 79,5-175,0 g a 69,5 g. No entanto, o teor de sólidos solúveis totais da polpa foi menor, de 7,59-10,88 e 10,30 ${ }^{\circ}$ Brix, bem como o pH, de 3,63-3,93 e 3,85. Os frutos da Venezuela apresentaram coloração verde, amarela, alaranjada e vermelha.

O teor de sólidos solúveis $\left(13,30^{\circ} \pm 0,14^{\circ}\right.$ Brix $)$ do fruto tamarillo (Cyphomandra betacea) desta pesquisa foi cerca de quatro vezes maior quando comparado com os tomates (Lycopersicon esculentum) das cultivares Italiano AF7123, Débora Plus, Santa Cruz AF6165 e Delícia, os quais, segundo Raupp et al. (2009), apresentaram 3,5, 3,2, 2,9 e 3,0 ${ }^{\circ}$ Brix, respectivamente. Com relação ao $\mathrm{pH}$, o tamarillo apresentou valor médio $(4,19 \pm 0,11)$, próximo aos resultados obtidos para os tomates (Lycopersicon esculentum), os quais apresentaram $\mathrm{pH}$ de 4,2 (cultivar Italiano AF7123), 4,3 (cultivar Débora Plus), 4,2 (cultivar Santa Cruz AF6165) e 4,1 (cultivar Delícia).
O jambolão (Syzygium cumini Lamarck) usado como matéria-prima por Lago et al. (2006), também para o processamento de geleia, apresentou $9,0^{\circ}$ Brix para os sólidos solúveis e pH igual a 3,9, valores esses um pouco menores que os obtidos na presente pesquisa para o tamarillo, cujos valores médios foram de 13,26 ${ }^{\circ}$ Brix para os sólidos solúveis e pH 4,19.

Embora um fruto com alto teor de sólidos solúveis totais não seja necessariamente de boa qualidade, a ausência de alto teor de sólidos solúveis totais pode indicar baixa qualidade (BIANCO e PRATT, 1977). Segundo Silva e Giordano (2000), o teor de sólidos do tomate (Lycopersicon esculentum) comum afeta diretamente o rendimento da produção de produtos dele derivados. O teor de sólidos solúveis no fruto, além de ser uma característica genética da cultivar, é influenciado pela adubação, pela temperatura e pela irrigação.

O rendimento médio dos frutos em polpa integral, contendo sementes, foi de $83,3 \%$, indicando que o tamarillo apresenta uma grande quantidade de polpa aproveitável para a produção de geleia. A polpa integral incluiu as regiões do mesocarpo e do endocarpo, que correspondem à porção mucilaginosa locular. $O$ rendimento da polpa locular do fruto foi bem menor, igual a $51,5 \%$.

A caracterização dos protocolos para os processos de obtenção dos produtos 'geleias de tamarillo' em quantidades iguais a $1200 \mathrm{~g}$ de produto por processamento, resultando num total de $3600 \mathrm{~g}$, está apresentada resumidamente na Tabela 1.

Nos produtos dos tratamentos 2 e 3, os sólidos solúveis totais representaram $600 \mathrm{~g}$, sendo que a incorporação de $40 \%$ de polpa de tamarillo contribuiu

Tabela 1. Caracterização dos processos para a obtenção dos produtos 'geleias de tamarillo'.

\begin{tabular}{|c|c|c|c|}
\hline Processo & $\begin{array}{c}\text { Tratamento } 1 \\
\left(40^{\circ} \text { Brix/glicose) }\right.\end{array}$ & $\begin{array}{c}\text { Tratamento } 2 \\
\left(50^{\circ} \text { Brix/glicose }\right)\end{array}$ & $\begin{array}{c}\text { Tratamento } 3 \\
\left(50^{\circ} \text { Brix/sacarose) }\right.\end{array}$ \\
\hline \multicolumn{4}{|l|}{ Produto geleia } \\
\hline Massa total, g & 1200,00 & 1200,00 & 1200,00 \\
\hline Sólido solúvel total, ${ }^{\circ}$ Brix & 40 & 50 & 50 \\
\hline Pectina, \% & 4 & 2 & 2 \\
\hline Proporção de polpa do fruto, \% & 40 & 40 & 40 \\
\hline Tempo de cocção em fervura, min. & 40 & 40 & 40 \\
\hline \multicolumn{4}{|l|}{ Polpa do fruto ( $40 \%$ da geleia) } \\
\hline Massa da polpa, g & 480,00 & 480,00 & 480,00 \\
\hline Sólido solúvel total da polpa, ${ }^{\circ}$ Brix & 13,32 & 13,12 & 13,32 \\
\hline Massa de sólido solúvel total, g & 63,94 & 62,98 & 63,94 \\
\hline \multicolumn{4}{|l|}{ Ingredientes da geleia (g) } \\
\hline Polpa do fruto & 480,00 & 480,00 & 480,00 \\
\hline Açúcar & 416,06 & 537,02 & 536,06 \\
\hline Pectina & 48,00 & 24,00 & 24,00 \\
\hline Água & 255,94 & 158,98 & 159,94 \\
\hline Somatório & 1200,00 & 1200,00 & 1200,00 \\
\hline
\end{tabular}


com, respectivamente, 62,98 e 63,94 g (Tabela 1). 0 ingrediente açúcar foi incluído nos produtos desses tratamentos, 2 e 3, para completar as $600 \mathrm{~g}$ de sólidos solúveis de suas respectivas geleias. Na geleia do tratamento 1, contendo $40{ }^{\circ}$ Brix, a polpa de tamarillo, também incorporada em 40\%, contribuiu com 63,94 g do total de $480 \mathrm{~g}$ de sólidos solúveis do produto geleia.

Com relação ao rendimento, a polpa integral do fruto tamarillo contribuiu com 40,0 g. $100 \mathrm{~g}^{-1}$ do produto geleia de todos os tratamentos.

Em estudos preliminares, outros produtos de $40{ }^{\circ}$ Brix e contendo menos de $4 \%$ de pectina (2 ou 3\%), bem como produtos de $50{ }^{\circ}$ Brix e contendo menos de $2 \%$ de pectina ( 1,0 ou 1,5\%) foram processados; porém, todos esses produtos apresentaram, visualmente, consistência na embalagem considerada 'mole' e uma espalhabilidade excessiva sobre uma superfície plana, para esse tipo de produto. Tais produtos foram, por isso, desclassificados e seus protocolos de processamento não foram recomendados para avaliação nesta proposta de pesquisa.

Os resultados médios obtidos no teste de aceitabilidade da geleia de tamarillo são mostrados na Tabela 2. Na Tabela 3, estão apresentadas as porcentagens de aceitação, indiferença e rejeição, associadas às amostras por meio das escalas hedônicas utilizadas, correspondentes às porcentagens de valores da escala de 9 a 6 (acima do ponto médio), 5 (ponto médio) e de 4 a 1 (abaixo do ponto médio), respectivamente, atribuídos pelos consumidores consultados; também são indicadas na Figura 3 as porcentagens de classificações acima do ideal (valores 5 e 4 da escala), ideal (valor 3) e abaixo do ideal (valores 2 e 1 da escala) para o umedecimento em pão de fôrma, bem como as porcentagens de intenção positiva de compra (valores 5 e 4 da escala), incerteza (valor 3) e intenção negativa de compra (valores 2 e
1 da escala). Os gostos e desgostos descritos pelos consumidores são apresentados nas Tabelas 4 e 5.

$\mathrm{Na}$ avaliação da aceitabilidade da aparência, do aroma e da espalhabilidade na torrada (Tabela 2), não houve diferença significativa $(p>0,05)$ entre as amostras das geleias que apresentaram médias próximas de "gostei", na escala empregada. Quanto ao sabor e ao produto de modo global, as amostras das geleias identificadas por $50^{\circ} \mathrm{Brix} / \mathrm{glicose}$ (tratamento 2) e por $50^{\circ}$ Brix/sacarose (tratamento 3), com médias situadas entre "gostei" e "gostei pouco", não diferiram significativamente entre si, mas, diferiram da amostra da geleia de $40^{\circ} \mathrm{Brix} /$ glicose (tratamento 1), que obteve médias situadas entre "gostei pouco" e "não gostei, nem desgostei", na escala empregada. Em relação à consistência na boca, também não houve diferença significativa entre as amostras de geleias do tratamento 2 e 3, que apresentaram médias próximas de "gostei" e diferiram significativamente da amostra de geleia do tratamento 1, 40 Brix/glicose, que obteve média correspondente a "gostei pouco", na escala empregada. Quanto à intensidade do umedecimento em pão de fôrma, as amostras das três geleias avaliadas apresentaram médias próximas a "do jeito que eu gosto" e não diferiram significativamente entre si no nível de 5\%. Quanto à intenção de compra, as amostras das duas geleias de $50{ }^{\circ}$ Brix contendo glicose (tratamento 2) ou sacarose (tratamento 3) apresentaram médias próximas de "talvez comprasse, talvez não comprasse" e não diferiram significativamente $(p>0,05)$ entre si, tendo diferido da amostra de geleia de $40{ }^{\circ}$ Brix/glicose (tratamento 1 ), com média situada entre "talvez comprasse, talvez não comprasse" e "provavelmente não compraria".

A amostra de geleia de $40^{\circ}$ Brix/glicose do tratamento 1 apresentou as maiores frequências de rejeição para o sabor, a consistência na boca e o produto de modo global e, como consequência, a mais elevada frequência de intenção negativa de compra (Tabela 3).

Tabela 2. Avaliação da aceitabilidade, intensidade do umedecimento em pão e intenção de compra das geleias de tamarillo pelo grupo de consumidores que avaliou as amostras.

\begin{tabular}{|c|c|c|c|c|}
\hline \multirow{2}{*}{ Aceitabilidade/Intensidade } & \multicolumn{3}{|c|}{ Tratamentos } & \multirow{2}{*}{ DMS } \\
\hline & $40^{\circ}$ Brix/glicose & $50^{\circ}$ Brix/glicose & $50{ }^{\circ}$ Brix/sacarose & \\
\hline Aparência & $7,0 \pm 1,1^{\mathrm{a}}$ & $6,9 \pm 1,4^{a}$ & $7,1 \pm 1,4^{a}$ & 0,42 \\
\hline Aroma & $6,5 \pm 1,4^{a}$ & $6,8 \pm 1,3^{a}$ & $6,7 \pm 1,4^{a}$ & 0,39 \\
\hline Sabor & $5,5 \pm 2,1^{b}$ & $6,3 \pm 1,8^{a}$ & $6,5 \pm 1,8^{a}$ & 0,70 \\
\hline Consistência na boca & $5,9 \pm 1,8^{b}$ & $6,8 \pm 1,5^{a}$ & $6,8 \pm 1,6^{a}$ & 0,61 \\
\hline Espalhabilidade na torrada & $6,6 \pm 1,4^{\mathrm{a}}$ & $6,8 \pm 1,5^{a}$ & $6,9 \pm 1,5^{\mathrm{a}}$ & 0,63 \\
\hline Modo global & $5,4 \pm 2,0^{b}$ & $6,1 \pm 1,7^{\mathrm{a}}$ & $6,7 \pm 1,8^{\mathrm{a}}$ & 0,66 \\
\hline Intensidade ideal de umedecimento em pão de fôrma & $2,7 \pm 0,7^{a}$ & $2,7 \pm 0,6^{a}$ & $2,9 \pm 0,7^{a}$ & 0,27 \\
\hline Intenção de compra & $2,6 \pm 1,3^{b}$ & $3,2 \pm 1,2^{\mathrm{a}}$ & $3,4 \pm 1,3^{a}$ & 0,43 \\
\hline
\end{tabular}

Média \pm desvio padrão; DMS: diferença mínima significativa $(p \leq 0,05)$ pelo Teste de Tukey; em cada linha, valores seguidos de letras iguais não diferem estatisticamente entre si $(p \leq 0,05)$. 
Tabela 3. Frequências de aceitação, indiferença e rejeição em relação às características sensoriais do produto, às frequências de intensidade de umedecimento em pão de fôrma e às frequências de intenção de compra das geleias de tamarillo.

\begin{tabular}{|c|c|c|c|c|}
\hline \multirow{2}{*}{\multicolumn{2}{|c|}{ Aceitabilidade/Intensidade }} & \multicolumn{3}{|c|}{ Tratamentos } \\
\hline & & $40^{\circ}$ Brix/glicose & $50^{\circ}$ Brix/glicose & $50{ }^{\circ}$ Brix/sacarose \\
\hline \multirow{3}{*}{ Aparência } & Aceitação (\%) & 94,0 & 92,0 & 90,0 \\
\hline & Indiferença (\%) & 4,0 & 2,0 & 2,0 \\
\hline & Rejeição (\%) & 2,0 & 6,0 & 8,0 \\
\hline \multirow[t]{3}{*}{ Aroma } & Aceitação (\%) & 84,0 & 92,0 & 86,0 \\
\hline & Indiferença (\%) & 4,0 & 2,0 & 2,0 \\
\hline & Rejeição (\%) & 12,0 & 6,0 & 12,0 \\
\hline \multirow[t]{3}{*}{ Sabor } & Aceitação (\%) & 64,0 & 82,0 & 78,0 \\
\hline & Indiferença (\%) & 2,0 & 2,0 & 8,0 \\
\hline & Rejeição (\%) & 34,0 & 16,0 & 14,0 \\
\hline \multirow{3}{*}{$\begin{array}{l}\text { Consistência } \\
\text { na boca }\end{array}$} & Aceitação (\%) & 70,0 & 92,0 & 86,0 \\
\hline & Indiferença (\%) & 8,0 & 0,0 & 6,0 \\
\hline & Rejeição (\%) & 22,0 & 8,0 & 8,0 \\
\hline \multirow{3}{*}{$\begin{array}{l}\text { Espalhabilidade na } \\
\text { torrada }\end{array}$} & Aceitação (\%) & 88,0 & 90,0 & 88,0 \\
\hline & Indiferença (\%) & 0,0 & 0,0 & 2,0 \\
\hline & Rejeição (\%) & 12,0 & 10,0 & 10,0 \\
\hline \multirow{3}{*}{$\begin{array}{l}\text { Produto de Modo } \\
\text { global }\end{array}$} & Aceitação (\%) & 60,0 & 76,0 & 84,0 \\
\hline & Indiferença (\%) & 0,0 & 6,0 & 6,0 \\
\hline & Rejeição (\%) & 40,0 & 18,0 & 10,0 \\
\hline \multirow{3}{*}{$\begin{array}{l}\text { Intensidade do } \\
\text { umedecimento em } \\
\text { pão de fôrma }\end{array}$} & Mais intenso que o ideal (\%) & 8,0 & 4,0 & 8,0 \\
\hline & Ideal (\%) & 62,0 & 70,0 & 72,0 \\
\hline & Menos intenso que o ideal (\%) & 30,0 & 26,0 & 20,0 \\
\hline \multirow[t]{3}{*}{ Intenção de compra } & Positiva (\%) & 32,0 & 40,0 & 48,0 \\
\hline & Incerteza (\%) & 16,0 & 24,0 & 28,0 \\
\hline & Negativa (\%) & 52,0 & 36,0 & 24,0 \\
\hline
\end{tabular}

Aceitação: pontuação 9 a 6; Indiferença: pontuação 5; Rejeição: pontuação 4 a 1; Mais intenso que o ideal: pontuação 5 e 4; Ideal: pontuação 3; Menos intenso que o ideal: pontuação 2 e 1; Positiva: pontuação 5 e 4; Incerteza: pontuação 3; Negativa: pontuação 2 e 1.

A amostra de geleia de $50^{\circ}$ Brix/sacarose do tratamento 3 destacou-se quando comparada aos produtos $50^{\circ}$ Brix por apresentar menor porcentual de rejeição em relação ao produto de modo global e menor intenção negativa de compra, embora ambas as geleias dos tratamentos 2 e 3 tenham apresentado baixa intenção positiva de compra (inferior a 50\%).

A frequência de aceitação (Tabela 3) das geleias de $50^{\circ}$ Brix contendo glicose (tratamento 2) ou sacarose (tratamento 3) foi alta para qualquer dos atributos sensoriais avaliados, sendo o 'modo global' da geleia com glicose o que obteve a menor porcentagem de aceitação (76\%) entre os provadores. Um porcentual de $70-72 \%$ dos provadores aprovou essas geleias como ideais para a intensidade do umedecimento em pão de fôrma (Tabela 3). Também, 40-48\% mostraram intenção para a compra desses produtos, sendo que $24-28 \%$ apresentaram dúvidas para a compra (Tabela 3).

Quanto aos gostos e desgostos descritos pelos consumidores, a amostra de geleia de $50^{\circ} \mathrm{Brix} / \mathrm{glicose}$ (Tratamento 2) recebeu um total de menções positivas referentes à consistência e à espalhabilidade na torrada superior às demais (Tabela 4), enquanto a amostra de geleia de $40{ }^{\circ}$ Brix/glicose (Tratamento 1) destacou-se negativamente em relação ao sabor (Tabela 5).

Portanto, pode ser inferido que as geleias dos tratamentos 2 e 3 , as quais continham as mesmas concentrações para os sólidos solúveis (50 ${ }^{\circ}$ Brix) e para a pectina (2\%), mas açúcar distinto, sacarose ou glicose, apresentaram similaridade na avaliação para qualquer dos atributos sensoriais, bem como para a intenção de compra dos produtos. Assim, apesar da diferenciação desses ingredientes quanto ao grau de doçura (sacarose é mais doce que a glicose), tal característica não se refletiu na aceitação e nem na intenção de compra desses produtos.

Com relação aos atributos sensoriais relacionados com a consistência dos produtos, somente para aqueles que foram avaliados visualmente, como a espalhabilidade na torrada e a intensidade de umedecimento em pão de fôrma, as geleias de todos os tratamentos não apresentaram diferença expressiva (Tabela 2). No entanto, para a consistência avaliada na boca, a geleia de $40^{\circ} \mathrm{Brix}$ (Tratamento 1) foi a que obteve a menor aceitação, o que pode ser atribuído, aparentemente, à alta porcentagem de pectina, $4 \%$ desse produto, o dobro dos demais. Além 
Desenvolvimento de geleia de tamarillo contendo polpa integral

GUILHERME, P. R. et al.

Tabela 4. Gostos descritos pelo grupo de consumidores que avaliou as geleias de tamarillo (números indicam a frequência com que foram citados).

\begin{tabular}{|c|c|c|c|}
\hline \multirow{2}{*}{ Gostos } & \multicolumn{3}{|c|}{ Tratamentos } \\
\hline & $40^{\circ}$ Brix/glicose & $50{ }^{\circ}$ Brix/glicose & $50{ }^{\circ}$ Brix/sacarose \\
\hline Aparência & 11 & 9 & 9 \\
\hline Cor & 8 & 4 & 6 \\
\hline Total de menções positivas sobre a aparência & 19 & 13 & 15 \\
\hline Total de menções positivas sobre o aroma & 11 & 7 & 9 \\
\hline Sabor & 12 & 15 & 16 \\
\hline Pouco sabor residual amargo & 1 & - & - \\
\hline Adoçamento & 2 & 3 & 5 \\
\hline Total de menções positivas sobre o sabor & 15 & 18 & 21 \\
\hline Consistência/textura & 10 & 11 & 8 \\
\hline Facilidade de espalhar & 6 & 6 & 5 \\
\hline Umedecimento & - & 1 & - \\
\hline Presença de pedaços & - & 1 & - \\
\hline Total de menções positivas sobre a consistência & 16 & 19 & 13 \\
\hline Total de menções positivas & 61 & 57 & 58 \\
\hline Nada, Não gostou & 5 & 2 & 2 \\
\hline
\end{tabular}

Tabela 5. Desgostos descritos pelo grupo de consumidores que avaliou as amostras de geleia de tamarillo (números indicam a frequência com que foram citados).

\begin{tabular}{|c|c|c|c|}
\hline \multirow{2}{*}{ Desgostos } & \multicolumn{3}{|c|}{ Tratamentos } \\
\hline & $40^{\circ}$ Brix/glicose & $50^{\circ}$ Brix/glicose & $50{ }^{\circ}$ Brix/sacarose \\
\hline Total de menções negativas sobre a aparência & - & 1 & - \\
\hline Total de menções negativas sobre o aroma & 1 & 3 & 1 \\
\hline Sabor & 18 & 9 & 6 \\
\hline Sabor estranho & - & - & 5 \\
\hline Sabor fraco & - & - & 1 \\
\hline Gosto ácido/azedo & 3 & 5 & 2 \\
\hline Amargo & 7 & 8 & 2 \\
\hline Adoçamento & 5 & - & 5 \\
\hline Total de menções negativas sobre o sabor & 33 & 22 & 21 \\
\hline Consistência/textura & 13 & 6 & 3 \\
\hline Presença de sementes/casca & 6 & 5 & 11 \\
\hline Presença de pedaços da fruta & - & 1 & 1 \\
\hline Difícil espalhar & 1 & 2 & 3 \\
\hline Umedecimento do pão & 1 & - & 1 \\
\hline Total de menções negativas sobre a consistência & 21 & 14 & 19 \\
\hline Total de menções negativas & 55 & 40 & 41 \\
\hline
\end{tabular}

da provável influência no atributo sensorial 'consistência na boca', a alta concentração $(4 \%)$ de pectina dessa geleia do Tratamento 1 , de $40{ }^{\circ}$ Brix, também deve ter influenciado negativamente no sabor desse produto.

Assim, ambas as geleias dos tratamentos 2 e 3 foram as mais aceitas para alguns dos atributos sensoriais avaliados (sabor, consistência na boca, modo global) e as que apresentaram uma maior intenção de compra que a geleia do Tratamento 1, de menor concentração de sólidos solúveis, $40{ }^{\circ}$ Brix, e maior concentração de pectina (4\%). A presença de uma maior quantidade de pectina na geleia de $40{ }^{\circ}$ Brix (de $4 \%$ contra $2 \%$ nas outras geleias) deve ter influenciado para a sua menor aceitação e menor intenção de compra por parte dos provadores. Dessa forma, mesmo tendo esse produto igual proporção de polpa (40\%) de tamarillo que aquelas geleias dos tratamentos 2 e 3 apresentam e ser o menos calórico (20\% menos, em quilocalorias), há uma menor aceitação e uma menor intenção de compra. Uma quantidade de 20,0 g de geleia representou 40 e $32 \mathrm{kcal}$ para os tratamentos 2 ou 3 (50 ${ }^{\circ}$ Brix) e 1 (40 ${ }^{\circ}$ Brix), respectivamente. 


\section{Conclusões}

Os frutos tamarillos apresentaram, em relação ao comprimento pedúnculo-ápice, ao diâmetro e à massa, valores iguais a, respectivamente, 54,8 \pm 4,0 mm, $34,6 \pm 2,4 \mathrm{~mm}$ e $36,2 \pm 6,5 \mathrm{~g}$. Os frutos renderam, respectivamente, 83,3 e $51,5 \%$ de polpa integral (mesocarpo e endocarpo) e polpa locular mucilaginosa (endocarpo), contendo sementes. A polpa integral, de sabor doce e levemente ácido, apresentou teor de sólidos solúveis, em ${ }^{\circ}$ Brix, de 13,30 \pm 0,14 e pH 4,19 \pm 0,11

As geleias apresentando concentração de sólidos solúveis de $50{ }^{\circ}$ Brix e contendo glicose ou sacarose não diferiram significativamente entre si para qualquer dos atributos sensoriais avaliados, nem para a intenção de compra. Essas geleias foram as mais aceitas pelos provadores, comparadas à geleia de menor concentração de sólidos solúveis, de 40 Brix. Um porcentual maior ou igual a $70 \%$ do total de provadores aprovou as geleias de $50{ }^{\circ}$ Brix para todos os seus atributos sensoriais avaliados e um mínimo de 40\% manifestou intenção de compra.

Considerando-se o custo de processo e o protocolo do processo de fabricação de geleia, o Tratamento de 50 Brix contendo o açúcar sacarose e $2 \%$ de pectina foi o recomendado, na pesquisa, para a produção de 'geleia de tamarillo'.

\section{Referências}

ASSOCIAÇÃO BRASILEIRADE EMPRESAS DE PESQUISA - ABEP. Critério de Classificação Econômica Brasil. ABEP, 2007. Disponível em: <www.abep.org/codigosguias/Criterio_ Brasil_2008.pdf>. Acesso em: 29 out. 2010.

BIANCO, V. V.; PRATT, H. K. Compositional changes in muskmelon during development and in response to athylene treatment. Journal of the American Society for Horticultural Science, Alexandria, v. 102, n. 1, p. 127-133, 1977.

BRASIL. Ministério da Saúde. Agência Nacional de Vigilância Sanitária - ANVISA. Resolução RDC n²72, de 22 de setembro de 2005. Aprova o Regulamento Técnico para produtos de vegetais, produtos de frutas e cogumelos comestíveis. Diário Oficial da República Federativa do Brasil, Brasília, DF, 23 set. 2005 .

INSTITUTO BRASILEIRO DE FRUTAS - IBRAF. Estatísticas Frutas Frescas. 2008. Disponível em: <www.ibraf.org.br/ estatisticas/Exportação/Comparativo_das_Exportações_

Brasileiras_de_Frutas_frescas_2007-2006.pdf>. Acesso em: 18 dez. 2010.

JACKIX, M. H. Doces, Geléias e Frutas em Calda. 2. ed. São Paulo: Editora da Unicamp, 1988. 98 p.
KISS, J. Estranhas no ninho. Globo Rural, Rio de Janeiro, ed. 210, abr. 2003. Disponível em: <www.revistagloborural. com/EditoraGlobo/componentes/article/edg_article_print/.... . Acesso em: 28 nov. 2010.

LAGO, E. S.; GOMES, E.; SILVA, R. Produção de geléia de jambolão (Syzygium cumini Lamarck): processamento, parâmetros físico-químicos e avaliação sensorial. Ciência e Tecnologia de Alimentos, Campinas, v. 26, n. 4, p. 847-852, 2006. http://dx.doi.org/10.1590/S0101-20612006000400021

LOPES, R. L. T. Dossiê Técnico-Fabricação de Geléias. Fundação Centro Tecnológico de Minas Gerais - CETEC; Serviço Brasileiro de Respostas Técnicas, 2007. Disponível em: <www. respostatecnica.org.br>. Acesso em: 20 mar. 2010.

LOURENZANI, A. E. B. S.; LOURENZANI, W. L.; BATALHA, M. $O$. Barreiras e oportunidades na comercialização de plantas medicinais provenientes da agricultura familiar. Informações Econômicas, São Paulo, v. 34, n. 3, p. 15-25, 2004.

MANZANO, J. E. Caracterización de frutos de tomate de arbol (Cyphomandra betaceae Cav. Sendtn.) y sus relativos em zonas montañosas de Venezuela. Interamerican Society for Tropical Horticulture, Caribe, v. 48, n. 10, p. 149-151, 2005.

MEILGAARD, M.; CIVILLE, G. V.; CARR, B. T. Sensory Evaluation Techniques. 4. ed. Boca Raton: CRC Press, 2006. $448 \mathrm{p}$.

MORTON, J. F. The tree tomato, or "tamarillo", a fast-growing, early-fruiting small tree for subtropical climates. Proceedings of the Florida Satte Horticultural Society, Florida, v. 95, p. 81-85, 1982.

RAUPP, D. S.; GARDINGO, J. S.; SCHEBESKI, L. S.; AMADEU, C. A.; BORSATO, a V. 2009. Processamento de tomate seco de diferentes cultivares. Acta Amazônica, Manaus, v. 39, n. 2, p. 415-422. http://dx.doi.org/10.1590/S004459672009000200021

RIBEIRO, E. P; SERAVALLI, E. A. G. Química de Alimentos. 2ed. São Paulo: Edgard Blücher, 2007. 184 p.

ROGER, A.; JUAN, M.; WILLIAM, M.; ANNE, V. Caracterización química y organoléptica de vino artesanal de tomate de arbol (Cyphomandra betaceae (Cav.) Sendth. Interamerican Society for Tropical Horticulture, Caribe, v.51, n. 10, p. 163-166, 2007.

SILVA, J. B. C.; GIORDANO, L. B. Tomate para Processamento Industrial. Brasília: Embrapa Comunicação para Transferência de Tecnologia; Embrapa Hortaliças, 2000. 169 p.

SOLER, M. P.; FADINI, A. L.; OKADA, C. E.; HILST, M. A. Frutas, Doce em Massa, Geléias e Frutas Cristalizadas para Micro e Pequna Empresa. Campinas: ITAL, 1995. v. 500, 73 p. 